\title{
VACINAS CONTRA A COVID-19: PRINCIPAIS PLATAFORMAS E BASES IMUNOLÓGICAS
}

\author{
Tércia Moreira Ribeiro da Silva' \\ ORCID: 0000-0002-5261-2266 \\ Carolina Braga de Resende" \\ ORCID: 0000-0002-2343-6013
}

Ana Clara Martins Santos Maia"' ORCID: 0000-0001-8743-2903

Stella Elizei de Pinho Malta"' ORCID: 0000-0003-4980-3421

Clebson Verissimo da Costa PereiralV ORCID: 0000-0003-4368-2645

Barbara Maximino Rezende ${ }^{v}$ ORCID: 0000-0001-7959-7732

'Departamento Materno Infantil e Saúde Pública, Escola de Enfermagem, Universidade Federal de Minas Gerais. Belo Horizonte, MG.

"Departamento de Atenção à Saúde do Trabalhador - DAST. Universidade Federal de Minas Gerais. Belo Horizonte, MG.

"'Centro de Pesquisas Clínicas, Faculdade de Medicina, Universidade Federal de Minas Gerais. Belo Horizonte, MG.

IV Sociedade Brasileira de Imunizações - SBIm. João Pessoa, PB.

vDepartamento de Enfermagem Básica, Escola de Enfermagem, Universidade Federal de Minas Gerais. Belo Horizonte, MG.

\footnotetext{
Autora Correspondente: Tércia Moreira Ribeiro da Silva

E-mail: terciaoliv@ufmg.br
}

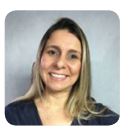

Como citar:

Silva TMR, Resende CB, Maia ACMS, et al. Vacinas contra a COVID-19: principais plataformas e bases imunológicas. In: Silva TMR, Lima MG, (Org.). Estratégias de vacinação contra a COVID-19 no Brasil: capacitação de profissionais e discentes de enfermagem. Brasilia, DF: Editora ABen; 2021.

P 41-51. (Série enfermagem e pandemias, 6). https://doi.org/10.51234/aben.21.e08.c05

Revisor: Renato Kfouri. Médico Pediatra. Primeiro secretário da SBIm e presidente do Departamento Científico de Imunizações da Sociedade Brasileira de Pediatria (SBP)

\section{INTRODUÇÃO}

As vacinas contra COVID-19 (do inglês, Corona Virus Disease) foram desenvolvidas e comercializadas em tempo recorde, mas não deixaram de atender às rigorosas etapas de testes pré-clínicos e clínicos para validação da segurança e eficácia ${ }^{(1-2)}$. O curto período de tempo transcorrido desde o sequenciamento do SARS-CoV-2 (do inglês, Severe acuterespiratory syndrome coronavirus 2) até a autorização da primeira vacina contra COVID-19, pode ser atribuído a diversos fatores, dentre eles, o conhecimento acumulado durante décadas, desde o desenvolvimento da primeira vacina ${ }^{(2)}$. Além disso, a pandemia do novo Coronavírus mobilizou pesquisadores do mundo todo e favoreceu o estabelecimento de parcerias e o compartilhamento das plataformas anteriormente desenvolvidas para combater os surtos da Síndrome Respiratória Aguda Grave (SARS-CoV) provocada por um Coronavírus identificado na província de Guangdong, na China em 2002 e da Síndrome Respiratória do Oriente Médio (MERS-CoV), identificada na Península Arábica em 2012 ${ }^{(2)}$.

Os países que instituíram a vacinação em massa contra a COVID-19, como Israel e Escócia, reduziram o número de casos e óbitos por COVID-19 e caminham em direção à recuperação econômica ${ }^{(3-6)}$. Contudo, alguns países da América Latina ainda enfrentam desafios para o alcance da imunidade coletiva, atribuídos, em parte, às políticas de austeridade e às crises políticas e econômicas que inviabilizaram o estabelecimento de estratégias para a vacinação em massa e em tempo oportuno nesses países ${ }^{(7)}$. No Brasil, o Programa Nacional de Imunizações (PNI), reconhecido internacionalmente pelas estratégias de vacinação que garantiram a eliminação e o controle de várias doenças infecciosas, resistiu aos cortes orçamentários ${ }^{(8)}$ e, atualmente, é responsável pela coordenação e distribuição das vacinas contra COVID-19 em todo o território nacional(9). De acordo com o Plano Nacional de vacinação contra a COVID-19, a Agência Nacional de Vigilância Sanitária (Anvisa) autorizou o uso emergencial das vacinas 
CoronaVac, produzida pelo Instituto Butantan, da Vacina contra COVID-19 (recombinante), produzida pelo Instituto de Tecnologia em Imunobiológicos Bio-Manguinhos / Fiocruz e, recentemente, concedeu o registro definitivo da vacina COVID-19 produzida pela Pfizer. O plano prevê ainda, que as estratégias de vacinação sejam coordenadas pelas Secretarias Estaduais de Saúde e operacionalizadas, no nível local, pelas Unidades Básicas de Saúde (UBS) dos municípios ${ }^{(10)}$.

Considerando que os profissionais de Enfermagem estão à frente das salas de vacinas das UBS e que serão responsáveis pela imunização da população brasileira contra a COVID-19, são imprescindíveis espaços para a abordagem dos princípios da imunização e das principais plataformas de vacinas contra a COVID-19 que estão em uso no Brasil e no mundo.

\section{SARS-COV-2: VISÃO GERAL}

OSARS-CoV-2 pertence à família Coronaviridae, ordem Nidovirales (latim: nidos, ninho e virales, relativo a vírus) e tem como material genético, um RNA de fita simples senso positivo, que fica enovelado às proteínas do Nucleocapsídeo viral (N)(11). O nome desta grande família de vírus: Coronavírus (CoVs), se deve a presença de espículas (estruturas proeminentes) que são visualizadas à microscopia eletrônica, dando uma aparência de coroa solar (corona em latim), nome dado ao envoltório luminoso que é formado ao redor do sol durante os eclipses solares ${ }^{(12-13)}$ (Figura 1).

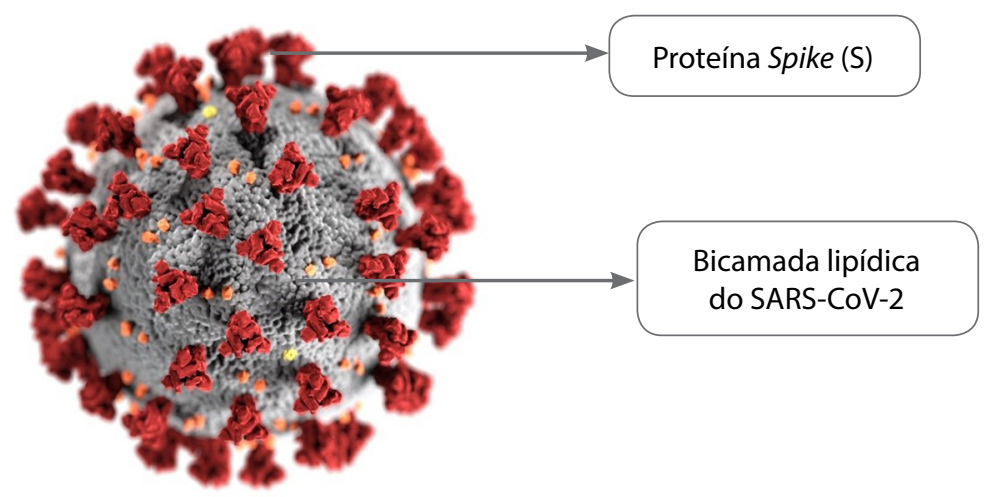

Figura 1. Representação esquemática dos antígenos do SARS-CoV-2. A bicamada lipídica do SARS-CoV-2 é constituída pela Proteína Spike (S), pela Proteína do Envelope (E) e pela Glicoproteína de Membrana (M) (E e M não estão representadas na figura).

Fonte $^{(14)}$ (adaptado)

Os CoVs são agentes etiológicos de infecções respiratórias, entéricas e sistêmicas em bovinos, suínos e pequenos roedores ${ }^{(13)}$. Em humanos, os CoVs são responsáveis por resfriados comuns, rinites, bronquiolites e pneumonias e foram identificados como causadores de infecções respiratórias em adultos e crianças, pela primeira vez, na década de $1960^{(3)}$. Os CoVs conhecidos pertencem a um dos seguintes gêneros: Alphacoronavírus, Betacoronavírus, Gammacoronavírus e Deltacoronavírus, sendo os CoVs dos gêneros Alphacoronavírus e Betacoronavírus, capazes de infectar seres humanos e causar enterites em outros mamíferos ${ }^{(11,12)}$. No gênero Betacoronavírus, podemos destacar os seguintes Coronavírus: o SARS-CoV, o MERS-CoV e o SARS-CoV-2, chamados de novos Coronavírus ${ }^{(11)}$.

Os vírus são intracelulares obrigatórios e, por isso, dependem de uma célula que forneça todo o maquinário celular para que eles possam replicar. O ciclo replicativo do SARS-CoV-2 não difere de outros vírus da mesma família, e objetiva a produção de progênies virais que poderão infectar outras células suscetíveis ${ }^{(14-15)}$. Para impedir que essas progênies virais sejam produzidas, as vacinas podem atuar em alguma das etapas do ciclo replicativo do vírus ${ }^{(14,16)}$.

Para o desenvolvimento das vacinas contra COVID-19, os pesquisadores elencaram, dentre as proteínas do SARS-CoV-2 (também chamadas de antígenos virais), aquelas que seriam capazes de estimular uma resposta imune mediada por linfócitos T (LT) - e suas subpopulações, e linfócitos B (LB) (Figura 2). 
A proteína Spike (S) foi selecionada por quase todas as plataformas de vacinas contra COVID-19(15,17), uma vez que anticorpos direcionados a esta proteína neutralizam o SARS-CoV-2, impedindo-o de adsorver às células susceptíveis à infecção pelo vírus, como as células do trato respiratório superior (células caliciformes e produtoras de muco), os pneumócitos tipo II, os enterócitos e as células endoteliais ${ }^{[20,21]}$ ).

Essas células possuem em comum, o receptor da Enzima Conversora de Angiotensina-2 (ECA-2) e a serina protease transmembrana 2 (TMPRSS2), que são utilizados pelo SARS-CoV-2 para a entrada nestas células ${ }^{(16)}$. Resumidamente, a proteína Spike (S) liga-se ao receptor da ECA-2 e, posteriormente, é clivada pela TMPRSS2 em duas partes: S1 e S2, permitindo que o SARS-CoV-2 entre na célula e inicie a replicação viral(16).

\section{PRINCÍPIOS DA VACINAÇÃO}

O princípio básico da vacinação consiste na administração de um microrganismo vivo atenuado ou morto (inteiro ou subunidades do microrganismo), que seja capaz de estimular uma resposta imune, impedindo que o indivíduo vacinado adoeça, caso ele entre em contato com o microrganismo futuramente ${ }^{(18)}$. A resposta imune direcionada ao microrganismo (antígeno vacinal) envolve a participação de células dendríticas, neutrófilos, monócitos, linfócitos T citotóxicos $\left(\mathrm{LTCD}^{+}\right)$, linfócitos T auxiliares (LT CD4 ${ }^{+}$), linfócitos $\mathrm{B}$, quimiocinas e citocinas pró-inflamatórias ${ }^{(18)}$. A proteção conferida pelas vacinas a longo prazo é mediada pelas células de memória que podem ser rapidamente reativadas em casos de reinfecção pelo mesmo patógeno (Figura 2).

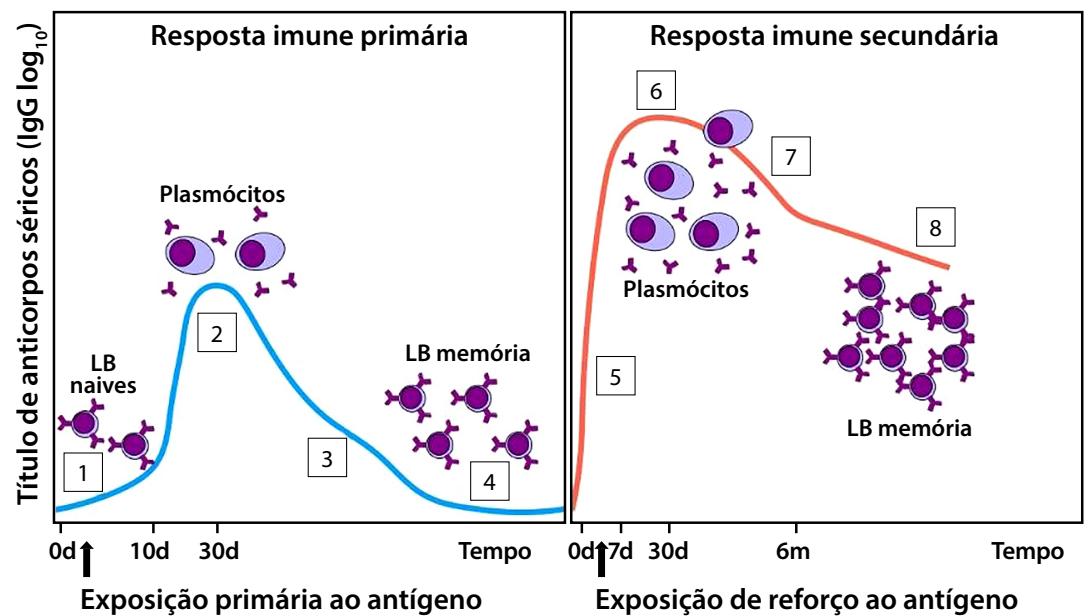

Figura 2. Titulação de anticorpos em diferentes fases de resposta à vacina.

A exposição inicial ao antígeno (1 ${ }^{a}$ dose da vacina) desencadeia uma resposta extrafolicular (isto é, fora do linfonodo) (1) que resulta no rápido aparecimento de títulos baixos de anticorpos $\mathrm{lg}$ G. À medida que linfócitos B proliferam nos centros germinativos dos linfonodos e se diferenciam em plasmócitos, os níveis de anticorpos $\mathrm{lg} G$ aumentam até um valor máximo (2), geralmente alcançado após quatro semanas da imunização. A vida curta dos plasmócitos resulta em um rápido declínio dos anticorpos (3), que eventualmente retornam aos níveis basais (4). Em respostas imunológicas secundárias, a exposição de reforço ao antígeno reativa a memória imunológica e resulta em um aumento rápido, menor que sete dias, dos níveis de lgG (5). Plasmócitos de vida curta mantêm o pico dos níveis de anticorpos durante algumas semanas (6). Depois disso, os títulos de anticorpos séricos diminuem inicialmente com a mesma cinética rápida após a imunização primária (7). Plasmócitos de vida longa que alcançaram nichos de sobrevivência na medula óssea continuam a produzir anticorpos específicos do antígeno, que em seguida, declinam com cinética mais lenta (8).

Fonte: Arquivo de imagens do autor.

\section{TIPOS DE VACINAS}

De acordo com a natureza do antígeno utilizado para a produção da vacina: microrganismo morto (inteiro ou partes dele) ou microrganismo vivo atenuado, as vacinas são classificadas em vacinas inativadas (vacinas mortas) ou vacinas vivas atenuadas (vacinas atenuadas), respectivamente ${ }^{(18)}$. Vale destacar, as novas tecnologias 
de vacinas inativadas que utilizam vetores virais e estratégias de engenharia genética. No citoplasma celular do indivíduo vacinado, são produzidas as proteínas ou os antígenos vacinais que são, posteriormente, apresentados para as células apresentadoras de antígenos, deflagrando a resposta imune. A vacina da Febre Amarela (FA), uma vacina viva atenuada, por exemplo, foi obtida por passagens sequenciais da cepa Asibi do vírus da FA em ovos embrionados, dando origem à cepa vacinal 17DD, que é utilizada pela Fiocruz para a produção da vacina FA no Brasil( ${ }^{(19)}$. Nas células do indivíduo vacinado, a cepa vacinal é capaz de se replicar, mimetizando uma infecção natural, mas sem causar a doença ${ }^{(19)}$.

Enquanto as vacinas vivas atenuadas são produzidas a partir do microrganismo vivo, as vacinas inativadas (ou mortas) são produzidas a partir do microrganismo morto, inteiro ou a partir de proteínas, polissacarídeos, ácido nucléico ou toxóides deste microrganismo ${ }^{(18)}$. As vacinas inativadas são menos imunogênicas do que as vacinas vivas atenuadas e, por isso, geralmente são necessárias doses de reforço após intervalos pré-estabelecidos para que essas vacinas confiram proteção ao indivíduo vacinado(18). Além disso, as vacinas inativadas quase sempre utilizam adjuvantes, compostos responsáveis pela otimização da resposta imune do indivíduo vacinado frente ao imunógeno ${ }^{(19)}$. Em termos gerais, estas vacinas possuem, além do antígeno, um adjuvante, que é adicionado à vacina e tem a função de "alertar" e ativar o sistema imunológico do hospedeiro, recrutando para o local da vacinação, inúmeras células de defesa. Os adjuvantes mais comuns são o hidróxido de alumínio, fosfato de alumínio, emulsões oleosas e saponinas ${ }^{(20)}$.

Além dos agentes imunizantes (mortos ou vivos atenuados) e dos adjuvantes (exclusivo para as vacinas mortas), as vacinas contêm também um líquido de suspensão, conservantes, estabilizadores e antibióticos ${ }^{(18)}$.

\section{RESPOSTA IMUNOLÓGICA FRENTE AOS ANTÍGENOS VACINAIS}

No caso das vacinas inativadas, o antígeno vacinal pode ser proteico ou polissacarídico, sendo a resposta imunológica, dependente do tipo de antígeno ${ }^{(18)}$. A resposta imune aos antígenos vacinais proteicos depende do reconhecimento desse antígeno pelos $\mathrm{LT} C D 4^{+}$que, por sua vez, serão responsáveis pela estimulação da diferenciação e expansão clonal dos $\mathrm{LB}^{(18)}$. As proteínas são comumente chamadas de antígenos T-dependentes e são capazes de estimular a proliferação e diferenciação de LT CD4+ efetores, essenciais para a memória imunológica ${ }^{(18)}$. Os antígenos de vacinas de polissacarídeos, por sua vez, estimulam somente a resposta imune humoral independente de células T, uma vez que os $\mathrm{LT} C D 4^{+}$não reconhecem antígenos polissacarídicos ${ }^{(18)}$. Nesse caso, 0 antígeno vacinal, também chamado de $T$-independente, é apresentado diretamente às células $B$, sem o intermédio dos linfócitos T e, consequentemente, não ocorre a proliferação e diferenciação de LT CD4+ efetores, essenciais para a memória imunológica ${ }^{(18)}$.

As vacinas vivas atenuadas, por sua vez, mimetizam uma infecção natural, sendo capazes de estimular fortemente a resposta imune adaptativa além de $\mathrm{LTCD} 4^{+}$e $\mathrm{LTCD} 8^{+}$. Caso o indivíduo previamente vacinado com uma vacina viva atenuada seja infectado com o vírus selvagem, os linfócitos T de memória serão acionados, deflagrando as respostas imunes humorais e celulares. As vacinas inativadas, por sua vez, nem sempre são tão efetivas na estimulação das respostas imunes adaptativas quanto as vacinas vivas atenuadas ${ }^{(18)}$. Cabe ressaltar que ainda não foi licenciada ou autorizada para uso emergencial, nenhuma vacina contra COVID-19 que utiliza o SARS-CoV-2 atenuado ${ }^{(14)}$.

\section{PLATAFORMAS DAS VACINAS INATIVADAS CONTRA A COVID-19}

Até o momento, as seguintes plataformas foram utilizadas para a produção das vacinas contra COVID-19 (1,14,21):

- Vetor viral;

- Vírus inativado ou morto; 
- Vacinas genéticas de RNA mensageiro;

- Subunidade de proteína.

Independentemente da plataforma adotada pela vacina, é recomendado estabelecer o intervalo mínimo de 14 dias entre a vacina contra a COVID-19 e outras vacinas ${ }^{(22)}$. Isto se deve à escassez de estudos que avaliam a segurança e a possível interferência na resposta imune da vacina contra COVID-19, quando outras vacinas são administradas concomitantemente ${ }^{(9)}$. São exceções a esta recomendação: indivíduos com lesões potencialmente contaminadas com o Clostridium tetani e sem história de vacinação antitetânica e profilaxia da raiva humana pós-exposição ${ }^{(10)}$. A seguir, apresentaremos as principais plataformas utilizadas para a produção das vacinas contra a COVID-19, a resposta imune frente aos antígenos vacinais, e vantagens e limitações de cada uma delas. Além disso, vale destacar, o intervalo de 14 dias assegura que, caso seja notificado algum evento adverso após a administração das vacinas contra a COVID-19, este não seja confundido com o evento adverso de outra vacina administrada em conjunto ou com intervalo inferior a 14 dias.

\section{VACINAS DE RNA MENSAGEIRO (RNAm)}

A primeira etapa para a produção das vacinas de RNA mensageiro (RNAm) consiste na identificação da sequência de nucleotídeos que, ao ser traduzida, será responsável pela codificação da proteína Spike ${ }^{(1)}$. A partir desta sequência, o RNAm é sintetizado em laboratório e, posteriormente, é revestido por uma nanopartícula lipídica que tem a função de proteger o RNAm da degradação por enzimas que estão presentes nos tecidos e fluidos do indivíduo vacinado. No citoplasma celular do indivíduo vacinado, o RNAm é traduzido em proteína Spike ${ }^{(17)}$. A expressão das proteínas Spike na superfície dessas células e o reconhecimento destas proteínas pelas células apresentadoras de antígenos, dá início à resposta imune ${ }^{(14,23)}$. É importante destacar que o RNAm é totalmente sintético e não é incorporado ao material genético do indivíduo vacinado e, portanto, não modifica o seu DNA ${ }^{(24)}$. Dentre as vantagens das vacinas de RNAm, destacam-se a segurança, facilidade e a rapidez para a produção em larga escala(24). As desvantagens das vacinas que utilizam esta plataforma estão associadas às baixas temperaturas de armazenamento, essenciais para que o RNAm não seja degradado e seu maior custo(1).

Até o momento, duas vacinas de RNAm estão aprovadas para uso em alguns países:

- Vacina ComirnatyTM (Pfizer/Biontech);

- Moderna.

O Quadro 1 apresenta as principais características das vacinas que utilizam essa plataforma.

Quadro 1 - Características das principais vacinas contra a COVID-19 que utilizam a plataforma de vacinas de RNA mensageiro (RNAm)

\begin{tabular}{|c|c|c|c|c|c|}
\hline $\begin{array}{l}\text { Nome da } \\
\text { vacina / } \\
\text { laboratório } \\
\text { produtor }\end{array}$ & $\begin{array}{l}\text { RNAm } \\
\text { responsável } \\
\text { pela } \\
\text { expressão } \\
\text { da seguinte } \\
\text { proteína }\end{array}$ & $\begin{array}{l}\text { Esquema } \\
\text { vacinal }\end{array}$ & Eficácia & Eventos adversos & Fase do estudo \\
\hline $\begin{array}{l}\text { ARCT-021 / } \\
\text { Arcturus } \\
\text { Therapeutics }\end{array}$ & $\begin{array}{l}\text { Dados não } \\
\text { divulgados }\end{array}$ & $\begin{array}{l}\text { Estão sendo } \\
\text { testados dois } \\
\text { esquemas: } \\
\text { duas doses, } \\
28 \text { dias de } \\
\text { intervalo; } \\
\text { dose única } \\
\text { (33). }\end{array}$ & $\begin{array}{l}\text { Dados não } \\
\text { divulgados }^{(33)}\end{array}$ & $\begin{array}{l}\text { Dados não } \\
\text { divulgados }\end{array}$ & Fase $\|^{(33)}$ \\
\hline
\end{tabular}




\begin{tabular}{|c|c|c|c|c|c|}
\hline $\begin{array}{l}\text { Nome da } \\
\text { vacina / } \\
\text { laboratório } \\
\text { produtor }\end{array}$ & $\begin{array}{l}\text { RNAm } \\
\text { responsável } \\
\text { pela } \\
\text { expressão } \\
\text { da seguinte } \\
\text { proteína }\end{array}$ & $\begin{array}{l}\text { Esquema } \\
\text { vacinal }\end{array}$ & Eficácia & Eventos adversos & Fase do estudo \\
\hline $\begin{array}{l}\text { Comirnaty }^{\mathrm{Tm}} \\
\text { vacina } \\
\text { COVID-19/ } \\
\text { Pfizer/ } \\
\text { Biontech }\end{array}$ & $\begin{array}{l}\text { Proteína Spike } \\
(S)^{(21)}\end{array}$ & $\begin{array}{l}2 \text { doses, com } \\
\text { intervalo de } 3 \\
\text { semanas }^{(29)} \text {. }\end{array}$ & $\begin{array}{l}\text { Eficácia geral de } \\
95 \%^{(30)}\end{array}$ & $\begin{array}{l}\text { Quanto aos eventos } \\
\text { adversos pós-vacinais } \\
\text { sistêmicos, prevaleceram } \\
\text { aqueles classificados } \\
\text { como muito comuns, } \\
\text { ou seja, aconteceram } \\
\text { na proporção de } 1 \\
\text { para cada } 10 \text { pessoas } \\
\text { vacinadas: cefaleia, } \\
\text { diarreia, artralgia e } \\
\text { mialgia( }{ }^{(30)} \text {. Quanto às } \\
\text { alterações no local da } \\
\text { aplicação da vacina, } \\
\text { foram apontadas a dor, } \\
\text { fadiga, arrepios, pirexia e } \\
\text { inchaço }\end{array}$ & $\begin{array}{l}\text { Fase III } \\
\text { Indivíduos a partir } \\
\text { de } 12 \text { anos de idade } \\
\text { podem receber } \\
\text { a vacina e, no } \\
\text { momento, estão } \\
\text { sendo desenvolvidos } \\
\text { ensaios clínicos com } \\
\text { crianças a partir } \\
\text { dos seis meses de } \\
\text { idade }^{(31)}\end{array}$ \\
\hline $\begin{array}{l}\text { CVnCoV/ } \\
\text { CUREVAC }^{(34)}\end{array}$ & $\begin{array}{l}\text { Proteína Spike } \\
(\mathrm{S})^{(34)}\end{array}$ & $\begin{array}{l}2 \text { doses, com } \\
\text { intervalo de } 4 \\
\text { semanas }^{(34)} \text {. }\end{array}$ & $\begin{array}{l}\text { Dados não } \\
\text { divulgados }^{(34)} \text {. }\end{array}$ & Dados não divulgados ${ }^{(34)}$ & Fase II ${ }^{(34)}$ \\
\hline $\begin{array}{l}\text { mRNA-1273 / } \\
\text { Moderna }\end{array}$ & $\begin{array}{l}\text { Proteína Spike } \\
(\mathrm{S})^{(30)}\end{array}$ & $\begin{array}{l}2 \text { doses, com } \\
\text { intervalo de } 4 \\
\text { semanas }^{(30)} \text {. }\end{array}$ & $\begin{array}{l}\text { Eficácia de } 94.1 \% \\
\left(\mathrm{IC}_{95 \%}=89.3-96.8 \% ;\right. \\
\mathrm{p}<0.001)^{(35)} \text {. Ensaios } \\
\text { clínicos de Fase } \\
\text { I/ II: indivíduos } \\
\text { imunizados com duas } \\
\text { doses apresentaram } \\
\text { resposta imune } \\
\text { específica com alta } \\
\text { titulação de anticorpos } \\
\text { neutralizantes contra } \\
\text { o SARS-CoV-2 e forte } \\
\text { resposta celular (LT } \\
\text { CD8 }{ }^{+} \text {e LT CD4 }{ }^{+} \text {pela via } \\
\text { Th1)(30). }\end{array}$ & $\begin{array}{l}\text { Prevaleceram os } \\
\text { seguintes eventos } \\
\text { adversos locais: dor, } \\
\text { eritema e edema e } \\
\text { sistêmicos: dor de } \\
\text { cabeça, fadiga e } \\
\text { mialgia }^{(35)} \text {. }\end{array}$ & $\begin{array}{l}\text { Fase III - aprovada } \\
\text { para uso emergencial } \\
\text { em alguns países. A } \\
\text { vacina está sendo } \\
\text { testada em bebês (a } \\
\text { partir de seis meses) } \\
\text { e crianças (menores } \\
\text { de } 12 \text { anos de idade) } \\
\text { (36). }\end{array}$ \\
\hline
\end{tabular}

Fonte: Elaborado pelos autores.

\section{VACINAS DE VETORES VIRAIS}

As vacinas de vetores virais utilizam um vírus geneticamente modificado que funciona como um sistema de entrega de uma sequência do material genético do SARS-CoV-2 ${ }^{(17)}$. Os adenovírus, responsáveis por resfriados comuns em humanos e outros mamíferos, podem ser submetidos a estratégias de engenharia genética e utilizados como vetores, apresentando como vantagem o amplo tropismo celular e a capacidade de infectarem células independentemente de estarem em mitose ${ }^{(33)}$.

A maioria das plataformas que utilizam essa tecnologia selecionaram o trecho do material genético do SARS-CoV-2 que é responsável pela expressão da proteína Spike (S). No interior das células do indivíduo vacinado, a proteína Spike é transcrita e, posteriormente, é expressa na membrana celular, estimulando o seu reconhecimento pelas células do sistema imune ${ }^{(14)}$.

Após o processamento e apresentação dos antígenos virais pelas células apresentadoras de antígenos, os linfócitos T citotóxicos são recrutados para eliminar qualquer estrutura que expresse a proteína. Dessa forma, o corpo cria uma memória para futuras infecções pelo SARS-Cov-2, protegendo o indivíduo vacinado ${ }^{(33)}$. 
As vantagens das vacinas de vetores virais incluem a indução de resposta imune celular e humoral, além do armazenamento em temperaturas habituais: de $2^{\circ}$ a $8^{\circ} \mathrm{C}^{(24)}$. Em relação às desvantagens das vacinas que utilizam essa plataforma, destaca-se a imunidade prévia do indivíduo vacinado ao adenovírus, que eventualmente pode comprometer a imunogenicidade da vacina ${ }^{(30)}$. O Quadro 2 apresenta as principais características das vacinas que utilizam essa plataforma.

Quadro 2 - Características das principais vacinas contra a COVID-19 que utilizam a plataforma de vetor viral

\begin{tabular}{|c|c|c|c|c|}
\hline $\begin{array}{l}\text { Nome da vacina / } \\
\text { laboratório produtor }\end{array}$ & Vetor viral & Esquema vacinal & Eficácia & Fase do estudo \\
\hline $\begin{array}{l}\text { Vacina COVID-19 } \\
\text { (recombinante) / } \\
\text { Instituto de Tecnologia } \\
\text { Em Imunobiológicos } \\
\text { Bio-Manguinhos / } \\
\text { Fiocruz* }\end{array}$ & Adenovírus símio (ChAd) & $\begin{array}{l}2 \text { doses, com } \\
\text { intervalo de } 3 \text { meses. }\end{array}$ & $70.4 \%$ & $\begin{array}{l}\text { Fase III - Aprovada para } \\
\text { uso emergencial em } \\
\text { alguns países. }\end{array}$ \\
\hline $\begin{array}{l}\text { Covidencia/ } \\
\text { CanSino Biological }\end{array}$ & $\begin{array}{l}\text { Adenovírus humano } \\
\text { sorotipo } 5 \text { (Ad5) }\end{array}$ & $\begin{array}{l}\text { Dados não } \\
\text { divulgados. }\end{array}$ & $\begin{array}{l}\text { Dados não } \\
\text { divulgados. }\end{array}$ & $\begin{array}{l}\text { Fase I - Aprovada para } \\
\text { uso exclusivo de militares } \\
\text { chineses. }\end{array}$ \\
\hline $\begin{array}{l}\text { Sputnik V/Instituto } \\
\text { Gamaleya }\end{array}$ & $\begin{array}{l}\text { Adenovírus humano } \\
\text { sorotipo } 26 \text { (Ad26) e } \\
\text { Adenovírus humano } \\
\text { sorotipo } 5 \text { (Ad5) }\end{array}$ & $\begin{array}{l}2 \text { doses - } 1 \text { dose com } \\
\text { Ad26 e outra com } \\
\text { Ad5 - intervalo de } \\
21 \text { dias }\end{array}$ & $91.4 \%$ & Fases I e II. \\
\hline $\begin{array}{l}\text { Jansen da Companhia / } \\
\text { Johnson \& Johnson }\end{array}$ & $\begin{array}{l}\text { Adenovírus humano } \\
\text { sorotipo } 26 \text { (Ad26) }\end{array}$ & 1 dose & $\begin{array}{l}\text { Eficácia geral } \\
66,1 \%\end{array}$ & $\begin{array}{l}\text { Fase III - Aprovada } \\
\text { para uso emergencial } \\
\text { em alguns países. } \\
\text { Atualmente em pausa } \\
\text { para investigação de } \\
\text { eventos adversos. }\end{array}$ \\
\hline Fonte ${ }^{(37)}$ (adaptado) & & & & \\
\hline
\end{tabular}

\section{VACINAS DE VÍRUS INATIVADO CONTRA O SARS-COV-2}

As vacinas de vírus inativados são produzidas a partir da inoculação do agente infeccioso em cultivo celular seguida da inativação física e/ou química. Exemplos de vacinas que há bastante tempo utilizam esta tecnologia incluem a vacina inativada da poliomielite (VIP), e a vacina adsorvida da Hepatite $A^{(34)}$.

Para a produção das vacinas contra COVID-19 utilizando essa tecnologia, inicialmente, o SARS-CoV-2 é inoculado em um cultivo de células e após o período de incubação necessário para que ocorra a adsorção, replicação e produção de progênies virais em larga escala (in vitro), o SARS-CoV-2 é submetido ao processo de inativação química ${ }^{(34)}$. A inativação do SARS-CoV-2 é realizada a fim de impedir que o indivíduo adoeça após a administração da vacina. Contudo, mesmo após a inativação, a partícula viral é mantida íntegra, favorecendo a ativação do sistema imune ${ }^{(2)}$. As vacinas inativadas são mais seguras do que as vacinas que utilizam vírus vivo atenuados, por exemplo. No entanto, patógenos inativados podem falhar na indução de respostas adaptativas celulares, sendo necessária a adição de adjuvantes ${ }^{(12)}$. De forma geral, essa vacina ativa monócitos, e estes produzem o Interferon (IFN), citocina responsável pela proliferação de LT CD4 ${ }^{+}$que, por sua vez, ativam os linfócitos $B$, responsáveis pela secreção de anticorpos neutralizantes que atuarão bloqueando a infecção pelo SARS-CoV-2. Os linfócitos T citotóxicos, (LT CD8 $\left.{ }^{+}\right)$, também podem ser ativados, promovendo a morte de células infectadas com o vírus ${ }^{(1)}$. 
Até o momento, as seguintes vacinas que utilizam essa plataforma estão aprovadas para uso em alguns países:

- COVAXIN (BBV152), produzida pela empresa Bharat Biotech, India) (35);

- SARS-CoV-2 Vaccine Vero Cell/BBIBP-CorV, produzida pela empresa Sinopharm em Wuhan e em parceria com a Beijing Bio-Institute of Biological Products Co-Ltd (BIBP) em Beijing ${ }^{(35)}$.

- SARS-CoV-2 Vaccine (PiCoVacc/Coronavac), produzida pela empresa Sinovac, China//Instituto Butantan) ${ }^{(35)}$.

O Quadro 3 apresenta as principais características das vacinas que utilizam essa plataforma.

Quadro 3 - Características das principais vacinas contra a COVID-19 que utilizam a plataforma de vacinas inativadas

\begin{tabular}{|c|c|c|c|c|c|}
\hline $\begin{array}{l}\text { Nome da vacina } \\
\text { (laboratório } \\
\text { produtor) }\end{array}$ & $\begin{array}{l}\text { Cepa do vírus } \\
\text { Inativado + } \\
\text { adjuvante }\end{array}$ & $\begin{array}{l}\text { Esquema } \\
\text { vacinal }\end{array}$ & Eficácia & Eventos adversos & Fase do estudo \\
\hline $\begin{array}{l}\text { SARS-CoV-2 } \\
\text { Vaccine/ } \\
\text { PiCoVacc/ } \\
\text { Coronavac } \\
\text { (Sinovac, } \\
\text { China/Instituto } \\
\text { Butantan) }\end{array}$ & $\begin{array}{l}\text { CN2 de SARS- } \\
\text { CoV-2, isolada } \\
\text { do lavado } \\
\text { broncoalveolar } \\
\text { de pacientes } \\
\text { internados, e tem } \\
\text { relação com a } \\
\text { cepa } 2019-n C o V- \\
\text { BetaCoV/WIV04 } \\
\text { /2019, identificada } \\
\text { em Wuhan } \\
\text { Adjuvante: } \\
\text { Hidróxido de }^{(36)} \\
\text { Alumínio }^{(36)}\end{array}$ & $\begin{array}{l}\text { Aplicação } \\
\text { intramuscular } \\
\text { de } 2 \text { doses, com } \\
\text { intervalo entre } \\
14 \text { a } 28 \text { dias (os } \\
\text { estudos de fase } \\
2 \text { indicam uma } \\
\text { melhor resposta } \\
\text { imunológica } \\
\text { com intervalo } \\
\text { de } 28 \text { dias) }{ }^{(36)}\end{array}$ & $\begin{array}{l}\text { Brasil: } 50,35 \% \text { em } \\
\text { prevenir a infecção } \\
\text { sintomática, } 78 \% \text { na } \\
\text { prevenção de casos } \\
\text { leves que requerem } \\
\text { tratamento e } 100 \% \\
\text { de prevenção de } \\
\text { casos graves }{ }^{(3,36)} \\
\text { Turquia: } 83,5 \% \text { em } \\
\text { prevenir a infecção } \\
\text { sintomática } \\
\\
\text { Indonésia: } 65,3 \% \text { em } \\
\text { prevenir a infecção } \\
\text { sintomática }\end{array}$ & $\begin{array}{l}\text { Dor no local da } \\
\text { injeção, náusea, } \\
\text { diarreia, cefaleia, } \\
\text { fadiga, mialgia, } \\
\text { tosse, artralgia, } \\
\text { prurido, rinorreia, } \\
\text { odinofagia, } \\
\text { congestão nasal, } \\
\text { prurido, eritema, } \\
\text { edema local e } \\
\text { enduração. Todos } \\
\text { esses eventos } \\
\text { foram leves ou } \\
\text { moderados }^{(36,37)}\end{array}$ & $\begin{array}{l}\text { Fase III - } \\
\text { aprovada para } \\
\text { uso emergencial } \\
\text { em } 24 \text { países, } \\
\text { incluindo o } \\
\text { Brasil }^{(35)}\end{array}$ \\
\hline $\begin{array}{l}\text { COVAXIN/ } \\
\text { BBV152 } \\
\text { (Bharat Biotech, } \\
\text { India) }\end{array}$ & $\begin{array}{l}\text { NIV-2020-770 } \\
\text { de um paciente } \\
\text { com COVID-19 } \\
\text { identificada na } \\
\text { Índia pelo Instituto } \\
\text { Nacional de } \\
\text { Virologia do país } \\
\\
\text { Adjuvante: } \\
\text { hidróxido de } \\
\text { alumínio e } \\
\text { imidazoquinolina }\end{array}$ & $\begin{array}{l}\text { Aplicação } \\
\text { intramuscular } \\
\text { de } 2 \text { doses, com } \\
\text { intervalo de } 28 \\
\text { dias }^{(38)}\end{array}$ & $\begin{array}{l}80.6 \% \text { (Resultados } \\
\text { preliminares } \\
\text { divulgados na } \\
\text { mídia pela empresa } \\
\text { Bharat Biotech em } \\
\text { março de 2021) }\end{array}$ & $\begin{array}{l}\text { Dor no local da } \\
\text { injeção, cefaleia, } \\
\text { fadiga, febre e } \\
\text { náuseas ou vômitos. } \\
\text { Todos esses eventos } \\
\text { foram leves ou } \\
\text { moderados }^{(37)}\end{array}$ & $\begin{array}{l}\text { Fase III- aprovada } \\
\text { para uso } \\
\text { emergencial em } 9 \\
\text { países, incluindo a } \\
\text { Índia, Irã, México } \\
\text { e Paraguai }{ }^{(38)}\end{array}$ \\
\hline $\begin{array}{l}\text { SARS-CoV-2 } \\
\text { Vaccine Vero } \\
\text { Cell/BBIBP-CorV } \\
\text { (Sinopharm/ } \\
\text { Wuhan em } \\
\text { parceria com } \\
\text { a Beijing } \\
\text { Bio-Institute } \\
\text { of Biological } \\
\text { Products Co-Ltd } \\
\text { (BIBP)/ Beijing) }\end{array}$ & $\begin{array}{l}\text { SARS-CoV-2 } \\
19 \text { nCoV-CDC-Tan- } \\
\text { HB02 } \\
\text { Adjuvante: } \\
\text { hidróxido de } \\
\text { alumínio(35,39) }^{(35)}\end{array}$ & $\begin{array}{l}\text { Aplicação } \\
\text { intramuscular } \\
\text { de } 2 \text { doses, com } \\
\text { intervalo de } 21 \\
\text { a } 28 \text { dias }^{(39)}\end{array}$ & $\begin{array}{l}79.34 \% \text { (Resultados } \\
\text { preliminares } \\
\text { divulgados na } \\
\text { mídia pela empresa } \\
\text { Sinopharm.) }\end{array}$ & $\begin{array}{l}\text { Febre, fadiga, } \\
\text { inapetência, náusea, } \\
\text { constipação, } \\
\text { anormalidades } \\
\text { mucocutâneas, } \\
\text { cefaleia e prurido(26) }^{(26}\end{array}$ & $\begin{array}{l}\text { Fase III- BBIBP-CorV } \\
\text { aprovada para uso } \\
\text { emergencial em } 36 \\
\text { países, incluindo } \\
\text { Argentina, Peru, } \\
\text { Egito e Emirados } \\
\text { Árabes Unidos } \\
\\
\text { SARS-CoV-2 } \\
\text { Vaccine-Vero Cell } \\
\text { aprovada para } \\
\text { uso emergencial } \\
\text { na China e nos } \\
\text { Emirados Árabes } \\
\text { Unidos }^{(39)}\end{array}$ \\
\hline
\end{tabular}

(*)A vacina SARS-CoV-2 Vaccine-Vero Cell é assim nomeada quando se refere à vacina produzida em Wuhan pela empresa Sinopharm ou também pode ser chamada de BBIBP-CorV quando se refere à vacina produzida pela empresa Sinopharm em parceria com o Beijing Bio-Institute of Biological Products (BIBP). 


\section{PLATAFORMAS MENOS USUAIS}

Atualmente, 100 vacinas estão em fase de testes clínicos, sendo: 31 de subunidade de proteína, 14 de vetor viral não replicante, 10 de DNA, 16 de vírus inativado, 16 de RNA, 3 de vetor viral replicante, 5 de partícula semelhante a vírus (VLPs), 3 de células apresentadoras de antígenos e apenas 2 de vírus vivo atenuado ${ }^{(14)}$. A seguir, são apresentadas as plataformas menos usuais que estão sendo testadas para a produção de vacinas contra a COVID-19 (Quadro 4).

Quadro 4 - Plataformas menos usuais das vacinas candidatas contra a COVID-19

\begin{tabular}{|c|c|c|c|c|}
\hline $\begin{array}{l}\text { Plataforma de } \\
\text { vacinas }\end{array}$ & Antígenos & $\begin{array}{l}\text { Resposta de } \\
\text { anticorpos } \\
\text { neutralizantes / } \\
\text { Resposta de células T }\end{array}$ & $\begin{array}{l}\text { Via de } \\
\text { aplicação } \\
\text { da vacina }\end{array}$ & Imunogenicidade geral \\
\hline Vacina de DNA & Proteína Spike & $\begin{array}{l}\text { Não induz / Indução de } \\
\text { LT CD4 }{ }^{+} \text {e de LT CD8 }{ }^{+} \\
\text {fraca }\end{array}$ & IM & $\begin{array}{l}\text { Mais fraca do que a vacina } \\
\text { de RNAm; são necessárias } \\
\text { doses de reforço. }\end{array}$ \\
\hline $\begin{array}{l}\text { Vírus atenuado } \\
\text { vivo }\end{array}$ & $\begin{array}{l}\text { Antígenos virais } \\
\text { múltiplos }\end{array}$ & $\begin{array}{l}\text { Indução forte / Indução } \\
\text { de LT CD4 }{ }^{+} \text {e de LT } \\
\text { CD8 }{ }^{+} \text {forte }\end{array}$ & SC & $\begin{array}{l}\text { Excelente imunogenicidade, } \\
\text { sendo necessária apenas } \\
\text { uma dose da vacina para } \\
\text { conferir a proteção. }\end{array}$ \\
\hline $\begin{array}{l}\text { Vacina de } \\
\text { subunidade de } \\
\text { proteína }\end{array}$ & $\begin{array}{l}\text { Proteína Spike ou } \\
\text { RBD }\end{array}$ & $\begin{array}{l}\text { Indução forte / Indução } \\
\text { de LT CD4+ e de LT } \\
\text { CD8 }{ }^{+} \text {fraca }\end{array}$ & IM & $\begin{array}{l}\text { Fraca; são necessárias doses } \\
\text { de reforço. }\end{array}$ \\
\hline $\begin{array}{l}\text { Partícula } \\
\text { semelhante a vírus } \\
\text { (VLPs) }\end{array}$ & $\begin{array}{l}\text { Antígenos virais } \\
\text { múltiplos }\end{array}$ & $\begin{array}{l}\text { Indução forte / Indução } \\
\text { de LT CD4 }{ }^{+} \text {e LT CD8 } \\
\text { fraca }\end{array}$ & IM & $\begin{array}{l}\text { Fraca, mas ainda é superior } \\
\text { às vacinas de subunidades } \\
\text { de proteínas; são } \\
\text { necessárias doses de } \\
\text { reforço. }\end{array}$ \\
\hline
\end{tabular}

\section{CONSIDERAÇÕES FINAIS}

Os profissionais de Enfermagem estão à frente das salas de vacinas das UBS, centros de referência de vacinação e centros de pesquisa clínica, onde as vacinas candidatas são estudadas. Nos Centros de Saúde, o enfermeiro é responsável pela supervisão, planejamento e avaliação do processo de trabalho da equipe de enfermagem que atua nas salas de vacinas. Já nos centros de pesquisa clínica, o enfermeiro é responsável pela captação e seleção de voluntários, retenção do participante e realização de contatos frequentes a fim de esclarecer dúvidas e manter o vínculo do participante com o centro de pesquisa. Além disso, na pesquisa clínica, o enfermeiro administra o produto investigacional, podendo ser a vacina ou o placebo, conforme protocolo de cada estudo, e registra os eventos adversos possivelmente associados ao imunógeno. Nesse sentido, são imprescindíveis espaços para a abordagem e discussão dos princípios da imunização e das principais plataformas de vacinas contra COVID-19 que estão em uso no Brasil e no mundo, uma vez que os profissionais de enfermagem podem atuar desde as pesquisas clínicas até a administração das vacinas contra COVID-19, etapas essenciais para mitigar a disseminação do SARS-CoV-2. 


\section{REFERÊNCIAS}

1. Pollard AJ, Bijker EM. A guide to vaccinology: from basic principles to new developments. Nat Rev Immunol. 2021;21(2):83100. https://doi.org/10.1038/s41577-020-00479-7

2. Kuter BJ, Offit PA, Poland GA. The development of COVID-19 vaccines in the United States: why and how so fast? Vaccine. 2021;39(18):2491-5. https://doi.org/10.1016/j.vaccine.2021.03.077

3. Haas EJ, Angulo FJ, McLaughlin JM, Anis E, Singer SR, Khan F, et al. Impact and effectiveness of mRNA BNT162b2 vaccine against SARS-CoV-2 infections and COVID-19 cases, hospitalisations, and deaths following a nationwide vaccination campaign in Israel: an observational study using national surveillance data. Lancet. 2021;397(10287):1819-29. https://doi. org/10.1016/S0140-6736(21)00947-8

4. Leshem E, Wilder-Smith A. COVID-19 vaccine impact in Israel and a way out of the pandemic. Lancet. 2021;397(10287):1783-5. https://doi.org/10.1016/S0140-6736(21)01018-7

5. Torjesen I. Covid-19: First doses of vaccines in Scotland led to a substantial fall in hospital admissions. BMJ. 2021;372:n523. https://doi.org/10.1136/bmj.n523

6. Dean N. Hospital admissions due to COVID-19 in Scotland after one dose of vaccine. Lancet. 2021;397(10285):1601-3. https://doi.org/10.1016/S0140-6736(21)00765-0

7. Pevehouse JCW. The COVID-19 Pandemic, International Cooperation, and Populism. Int Organ. 2020;114(S1):E191-212. https://doi.org/10.1017/S0020818320000399

8. Menezes APR, Moretti B, Reis AAC. O futuro do SUS: impactos das reformas neoliberais na saúde pública: austeridade versus universalidade. Saúde Debate. 2019;43(spe5):58-70. https://doi.org/10.1590/0103-11042019S505

9. Ministério da Saúde (BR). Plano Nacional de Operacionalização da Vacinação Contra A COVID-19: Brasil Imunizado Somos uma só Nação [Internet]. 5. ed. Brasília: 2021 [cited 2021 Mar 29]. Available from: https://www.gov.br/saude/pt-br/media/ pdf/2021/marco/23/planovacinacaocovid_ed5_15-mar-2021_v2.pdf

10. Yan R, Zhang Y, Li Y, Xia L, Guo Y, Zhou Q. Structural basis for the recognition of SARS-CoV-2 by full-length human ACE2. Science. 2020;367(6485):1444-8. https://doi.org/10.1126/science.abb2762

11. Li G, Fan Y, Lai Y, Han T, Li Z, Zhou P, et al. Coronavirus infections and immune responses. J Med Virol. 2020;92(4):424-32. https://doi.org/10.1002/jmv.25685

12. Cevik M, Kuppalli K, Kindrachuk J, Peiris M. Virology, transmission, and pathogenesis of SARS-CoV-2. BMJ. 2020;371. https:// doi.org/10.1136/bmj.m3862

13. Kang S, Peng W, Zhu Y, Lu S, Zhou M, Lin W, et al. Recent progress in understanding 2019 novel coronavirus (SARS-CoV-2) associated with human respiratory disease: detection, mechanisms and treatment. Int J Antimicrob Agents. 2020;55(5). https://doi.org/10.1016/j.jiantimicag.2020.105950

14. Jeyanathan M, Afkhami S, Smaill F, Miller MS, Lichty BD, Xing Z. Immunological considerations for COVID-19 vaccine strategies. Nat Rev Immunol. 2020;20(10):615-32. https://doi.org/10.1038/s41577-020-00434-6

15. Forni G, Mantovani A, Forni G, Mantovani A, Moretta L, Rappuoli R, et al. COVID-19 vaccines: where we stand and challenges ahead. Cell Death Differ. 2021;28(2):626-39. https://doi.org/10.1038/s41418-020-00720-9

16. Hoffmann M, Kleine-Weber H, Schroeder S, Krüger N, Herrler T, Erichsen S, et al. SARS-CoV-2 Cell Entry Depends on ACE2 and TMPRSS2 and Is Blocked by a Clinically Proven Protease Inhibitor. Cell. 2020;181(2):271-280.e8. https://doi. org/10.1016/j.cell.2020.02.052

17. Ahmed SF, Quadeer AA, McKay MR. Preliminary identification of potential vaccine targets for the COVID-19 Coronavirus (SARS-CoV-2) Based on SARS-CoV Immunological Studies [Internet]. Viruses. 2020[cited 2021 May 17];12(3):254. Available from: http://www.allelefrequencies.net/

18. Zepp F. Principles of vaccination. In: Methods in Molecular Biology. Humana Press Inc.; 2016. p57-84. https://doi. org/10.1007/978-1-4939-3387-7_3

19. Davis EH, Beck AS, Strother AE, Thompson JK, Widen SG, Higgs S, et al. Attenuation of live-attenuated yellow fever 17D vaccine virus is localized to a high-fidelity replication complex. MBio. 2019;10(5). https://doi:10.1128/mBio.02294-19.

20. Schijns V, Fernández-Tejada A, Barjaktarović Ž, Bouzalas I, Brimnes J, Chernysh S, et al. Modulation of immune responses using adjuvants to facilitate therapeutic vaccination. Immunol Rev. 2020;296(1):169-90. https://doi.org/10.1111/imr.12889 
21. Nagy A, Alhatlani B. An overview of current COVID-19 vaccine platforms. Comput Struct Biotechnol J [Internet]. 2021[cited 2021 May 17]. Available from: http://www.ncbi.nlm.nih.gov/pubmed/33936564

22. Center for Disease and Control. Pfizer-BioNTech COVID-19 Vaccine Preparation and Administration Summary [Internet]. Atlanta, Geórgia, EUA: CDC; 2021 [cited 2021 May 17]. Available from: https://www.cdc.gov/vaccines/covid-19/info-byproduct/pfizer/downloads/prep-and-admin-summary.pdf

23. Xia S, Zhang $Y$, Wang $Y$, Wang $H$, Yang $Y$, Gao GF, et al. Safety and immunogenicity of an inactivated SARS-CoV-2 vaccine, BBIBP-CorV: a randomised, double-blind, placebo-controlled, phase 1/2 trial. Lancet Infect Dis. 2021;21(1):39-51. https:// doi:10.1016/S1473-3099(20)30831-8

24. Wyeth Indústria Farmacêutica Ltda. Bula ComirnatyTM vacina covid-19 [Internet]. 2021[cited 2021 May 17]. Available from: https://www.pfizer.com.br/sites/default/files/inline-files/Comirnaty_Profissional_de_Saude_06.pdf

25. Arcturus Therapeutics I. A Trial Evaluating the Safety and Effects of an RNA Vaccine ARCT-021 in Healthy Adults - Full Text View - ClinicalTrials.gov [Internet]. 2021[cited 2021 May 17]. Available from: https://clinicaltrials.gov/ct2/show/ NCT04668339

26. BioNTech SE. Study to Describe the Safety, Tolerability, Immunogenicity, and Efficacy of RNA Vaccine Candidates Against COVID-19 in Healthy Individuals - Full Text View - ClinicalTrials.gov. Natl Inst Health [Internet]. 2020[cited 2021 May 17]. Available from: https://clinicaltrials.gov/ct2/show/NCT04368728?term=BNT162b2\&draw=2\#studydesc

27. Corminaty, Pfizer, Biontech. COMIRNATYTM: Armazenamento da vacina e manuseio seguro do gelo seco[Internet]. Corminaty2021 [cited 2021 May 17];Available from: https://www.comirnatyeducation.com.br/resources

28. Rauch S, Roth N, Schwendt K, Fotin-Mleczek M, Mueller SO, Petsch B. mRNA-based SARS-CoV-2 vaccine candidate CVnCoV induces high levels of virus-neutralising antibodies and mediates protection in rodents. NPJ Vaccines. 2021;6(1):1-9. https://doi.org/10.1038/s41541-021-00311-w

29. Baden LR, El Sahly HM, Essink B, Kotloff K, Frey S, Novak R, et al. Efficacy and Safety of the mRNA-1273 SARS-CoV-2 Vaccine. N Engl J Med 2021;384(5):403-16. https://doi.org/10.1056/NEJMoa2035389

30. ModernaTX I. A Study to Evaluate Safety and Effectiveness of mRNA-1273 Vaccine in Healthy Children Between 6 Months of Age and Less Than 12 Years of Age - Full Text View - ClinicalTrials.gov [Internet]. 2021[cited 2021 May 17]. Available from: https://clinicaltrials.gov/ct2/show/NCT04796896

31. Walsh EE, Frenck RW, Falsey AR, Kitchin N, Absalon J, Gurtman A, et al. Safety and Immunogenicity of Two RNA-Based Covid-19 Vaccine Candidates. N Engl J Med [Internet]. 2020[cited 2021 May 17];383(25):2439-50. Available from: http:// www.nejm.org/doi/10.1056/NEJMoa2027906

32. Organização Pan-Americana da Saúde (PAHO), Organização Mundial da Saúde (OMS). Perguntas frequentes sobre as vacinas candidatas contra a COVID-19 e os mecanismos de acesso [Internet]. 2021 [cited 2021 May 17]. Available from: https://iris.paho.org/bitstream/handle/10665.2/53248/OPASFPLIMCOVID-19210004_por.pdf?sequence=1\&isAllowed=y

33. Kyriakidis NC, López-Cortés A, González EV, Grimaldos AB, Prado EO. SARS-CoV-2 vaccines strategies: a comprehensive review of phase 3 candidates. Vaccines. 2021;6(1):1-17. https://doi.org/10.1038/s41541-021-00292-w

34. Butantan. Bula da Vacina adsorvida covid-19 (inativada). Sinov. e Inst. Butantan; 2021;1-8.

35. Yan Z-P, Yang M, Lai C-L. COVID-19 Vaccines: A Review of the Safety and Efficacy of Current Clinical Trials. Pharmaceuticals (Basel) 2021;14(5). http://doi: 10.3390/ph14050406.

36. Sapkal GN, Yadav PD, Ella R, Deshpande GR, Sahay RR, Gupta N, et al. Neutralization of UK-variant VUI-202012/01 with COVAXIN vaccinated human serum. bioRxiv 2021;2021.01.26.426986. https://doi.org/10.1101/2021.01.26.426986

37. García-Montero C, Fraile-Martínez O, Bravo C, Torres-Carranza D, Sanchez-Trujillo L, Gómez-Lahoz AM, et al. An updated review of SARS-CoV-2 vaccines and the importance of effective vaccination programs in pandemic times. Vaccines. 2021;9(5):433. https://doi.org/10.3390/vaccines9050433

38. Shenzhen Kantai Biological Products Co. LTD. A study to evaluate the efficacy, safety and immunogenicity of SARS-CoV-2 Vaccine (Vero Cells), inactivated in healthy adults aged 18 years and older (COVID-19) [Internet]. 2020[cited 2021 Jun 1]. Available from: https://clinicaltrials.gov/ct2/show/NCT04510207

39. World Health Organization (WHO). Draft landscape and tracker of COVID-19 candidate vaccines [Internet]. Genebra: 2021 [cited 2021 May 17]. Available from: https://www.who.int/publications/m/item/ draft-landscape-of-covid-19-candidate-vaccines 